\title{
De la descentralización a la regionalización. Nuevo escenario de la guerra y oportunidad para la paz
}

\begin{abstract}
In many Latin-American countries, the combination among neoliberal politics of adjustment, economic opening and transformations to political regimes, modify both economic geognaphy and spatial conformation of institutions, political systems, social and corponative actors. Colombia has also been affected by this redesign, that compromises the openation of its external and internal politics. The spatial effects of the economic opening combine with those of administnative, fiscal, and political process of decentralization, generating a tension on the geognaphical unit of the State. The consideration of these tendencies that have marked the paths of the economic, institutional, political, and social transformations since twenty years ago, indicate a probable way toward the regionalization of the country. Will this regionalization be convenient for a more stable internal development and a favorable setting for a peace agreement based on a territorial distribution of the power, or will it be the promptest way to abandon each territory to its luck in the wonld competence, and to break the territorial unit of the Colombian State? This is the question that is presented here.
\end{abstract}

Keywords: descentralization, development, neoliberalism, Colombia.

\section{Resumen}

En muchos países latinoamericanos, la combinación entre políticas de ajuste neoliberal, apertura económica y transformaciones a los regímenes políticos, modifican tanto la geografía económica como la conformación espacial de las instituciones, los sistemas políticos, los actores empresariales y sociales. Colombia no es ajena a tal rediseño, que compromete el funcionamiento de sus políticas externas e internas. Los efectos espaciales de la apertura económica se combinan con los del proceso de descentralización política, fiscal y administrativa, generando una tensión sobre la unidad geográfica del Estado. La consideración de estas tendencias que desde hace veinte años han marcado los senderos de las transformaciones sociales, políticas, institucionales y económicas, indican un camino probable hacia la regionalización del país. ¿¿Será ésta conveniente para un desarrollo interno más equilibrado y un escenario propicio para un acuerdo de paz con base en una distribución territorial del poder, o por el contrario, el camino más expedito para abandonar cada territorio a su suerte en la competencia mundial y romper la unidad territorial del Estado colombiano? Tal es la inquietud que se deja aquí planteada.

Palabras clave: descentralización, desarrollo, neoliberalismo, Colombia. 


\section{Advertencia}

$\mathrm{E}$ n una buena cantidad de países de América Latina la combinación entre las políticas de ajuste neoliberal, la apertura económica y las transformaciones a los regímenes políticos, modifican tanto la geografía económica como la conformación espacial de las instituciones y los sistemas políticos y los actores empresariales y sociales ${ }^{1}$.

Colombia no es ajena a tal rediseño que compromete el funcionamiento de sus políticas externas e internas. Los efectos espaciales de la apertura económica se combinan con aquellos del proceso de descentralización política, fiscal y administrativa, al punto de generar una tensión sobre la unidad geográfica del Estado colombiano.

¿Cómo se dibujará el mapa colombiano en una veintena de años? No se sabe bien, pero se intuye que será sensiblemente difer ente al actual. La consideración de las tendencias que, desde una veintena de años atrás, han marcado los senderos de las transformaciones sociales, políticas, institucionales y económicas, indican un camino probable hacia la regionalización del país. ¿¿Será esta conveniente para un desarrollo interno más equilibrado y escenario propicio para un acuer do de paz con base en una distribución territorial del poder, o lo contrario, el camino más expedito para abandonar cada territorio a su suerte en la competencia mundial y romper la unidad territorial del Estado colombiano? Tal es la inquietud central que se deja aquí planteada.

La ciencia política es una disciplina diferente a la adivinación. Cuando se recogen las tendencias profundas de los acontecimientos y se pro-

\footnotetext{
* Profesor asociado de la Universidad Nacional de Colombia en la Escuela de Economía. Miembro de la Fundación para la Participación Comunitaria (Parcomún). E-mail: direstre@colomsat.net.co

1 La Red Iberoamericana de Investigadores sobre Globalización y Territorio (RII) ha organizado, desde 1994 siete encuentros para el estudio de estas relaciones. Su última publicación es "Globalización y territorio" (Castagna, Raposo y Woelfin, 2002). Para toda información se puede acudir a Sergio González, coordinador general de la RII. E-mail: sergiogonlop2@yahoo.com
}

yectan hacia el mañana se construye una simulación del probable escenario futuro; pero, la historia de los pueblos rara vez es tan obediente y predecible. El ejercicio de proyección sirve, sin embargo, para resaltar dilemas ineludibles que en todo caso deben enfrentarse en los acontecimientos venideros.

\section{Del Estado centralizado a la descentralización}

Una de las transformaciones más importantes inducidas por el proceso de descentralización es el tránsito de una sistema institucional relativamente centralizado y rígido, a otro, plural y flexible. Las demandas por una sociedad y un régimen político más pluralistas, han destapado los diques sobre los cuales se mantuvo el Estado unitario centralizado. Ahora se practica y se reclama profundizar más el pluralismo en el ordenamiento territorial, normativo, político, étnico y cultural.

Durante un siglo, desde la constitución de 1886 a la reforma de 1986, la construcción del Estado Nación colombiano adoptó la forma unitaria, centralista y presidencialista. Para dar término al período de "La Violencia" (1948-1953)2, los partidos tradicionales apoyaron el golpe militar del general Gustavo Rojas Pinilla, que años después fue derrocado por un paro cívico bajo el auspicio de liberales, una fracción de conservadores, gremios, sindicatos y hasta la jerarquía eclesiástica. Al "golpe de opinión" le sucedió, en 1957, la realización de un plebiscito que añadió como característica básica del panorama colombiano, el régimen político bipartidista ${ }^{3}$.

Tres de los rasgos fundamentales del Estado y del régimen político colombiano, el centralismo, el presidencialismo y el bipartidismo, han sufrido

\footnotetext{
${ }^{2}$ Con el nombre de "la violencia" se conoce el enfrentamiento guerrero entre los dos partidos tradicionales colombianos, el liberal y el conservador, que dejó aproximadamente 300.000 muertos y dos millones de desplazados internos, generalmente del campo a las ciudades.

${ }^{3}$ Los partidos tradicionales hicieron refrendar su acuerdo político de paz para instituir una repartición milimétrica del poder durante 16 años, el que se prolongó como "repartición adecuada y equitativa” del poder hasta 1986.
} 
un deterioro importante en los últimos quince años. La inquietud obvia que surge es si el carácter unitario del Estado podrá sobrevivir al derrumbe de los pilares institucionales y políticos sobre los cuales se erigió.

La reversión del péndulo ocurre en la década del ochenta del siglo XX con la profundización de un proceso de descentralización que se insinuó desde la década del sesenta. El presidente no nombra más los gobernadores, quienes, a su vez, no nombran más a los alcaldes. En la actualidad cada mandatario obtiene una legitimidad propia otorgada por los electores de cada jurisdicción territorial. El presidente no dispone más de sus "agentes políticos directos" en los municipios y departamentos; estos pueden contrariarlo, criticarlo e, incluso, oponerse abier tamente a sus directrices políticas. El "orden público" es responsabilidad exclusiva del presidente, el cual lo usa como férula para obligar respeto y sometimiento de alcaldes y gobernadores a sus estrategias de manejo de los conflictos sociales agudos y del conflicto armado. Pero incluso en estos casos, los mandatarios locales no solo reclaman mayor protagonismo, sino que muchas veces lo ejercen a espaldas o en abierto desafío a las autoridades de la Casa de Nariño ${ }^{4}$.

En vir tud de la transferencia de casi el 50\% de los ingresos corrientes de la nación a las entidades territoriales, las autoridades económicas, ministerios y departamentos administrativos centrales han perdido ascendencia sobre el uso que los mandatarios locales hacen de los recursos recibidos. El resultado es un debilitamiento del centralismo. Claro está que los giros realizados poseen en su mayoría una destinación específica. En ese sentido, los mandatarios locales no disponen a su arbitrio de las transferencias. Pero no menos claro es que los funcionarios del alto gobierno también se encuentran constreñidos por la misma limitación y que grandes objetivos de la política económica nacional dependen del desempeño que logren las

\footnotetext{
${ }^{4}$ El último acontecimiento -dramático como pocos- de esta tendencia a desarrollar acercamientos y negociaciones con la insurgencia de manera paralela a la política del ejecutivo central, fue realizado por la gobernación de Antioquia respecto de su gobernador y asesor de paz, secuestrados por las FARC y asesinados por ésta, como retaliación a un intento de liberación por el ejército nacional.
}

entidades territoriales. Por ejemplo, el control del circulante monetario para disminuir la inflación es una prioridad del Banco de la República que está constreñida por el respeto a los montos girados en vir tud de la descentralización y ello, independientemente de la disponibilidad presupuestal. De la misma manera, el objetivo de reducción del déficit fiscal encuentra en el automatismo de las transferencias una gran dificultad. Lo mismo puede afirmarse de la brega por una mayor eficiencia del gasto público que depende, aproximadamente en el $15 \%$ del producto interno bruto, del desempeño que logren los gobiernos locales, muchas veces en asocio con programas y funcionarios del orden nacional.

En la reducción de la inflación y el déficit fiscal y en el aumento de la eficiencia del gasto público, las autoridades centrales todavía poseen una capacidad de coerción sobre los gobiernos locales, que proviene del origen nacional de las transferencias y del monopolio que ejerce el Congreso sobre la creación de tributos. En virtud de las solicitudes de crédito por las entidades locales al gobierno nacional, este último impone pactos de reducción de gastos, bur ocracia, salarios e incide sobre la organización y políticas de las administraciones locales. Existe, entonces, un "empate técnico", en el que el centro depende de la periferia para cumplir sus objetivos centrales de política económica y los gobiernos locales dependen de la financiación nacional para acometer gran parte de la inversión en sus territorios.

¿Hasta cuándo durará este empate técnico? ¿Logrará consolidarse como un buen arreglo de mutua dependencia y balance entre poderes nacionales y locales? ¿O las tensiones que generan el conflicto armado y la crisis económica, que se prolonga desde el colapso de 1999 a la fecha, quebrarán el precario equilibrio, lanzando al país hacia un neocentralismo o hacia un salto en la profundización de la descentralización?

Autoridades centrales pugnan, desde hace más de una década, por reducir el nivel de transferencias e intervenir más en el destino y uso de las competencias delegadas, así como por recortar la autonomía de los gobiernos locales, a causa del conflicto armado y de la lucha contra el tráfico de estupefacientes. Mientras tanto, las autoridades 
locales, de todo tinte político, demandan mayor autonomía en el manejo de recursos y competencias y, en los casos de los departamentos, acrecentar sensiblemente su capacidad fiscal. Algunos mandatarios locales solicitan con fuerza cambios en la estrategia de substitución de cultivos ilícitos adelantando planes de desarrollo alternativos. Los dos últimos grandes acontecimientos en esta disputa entre el centro y la periferia fueron, de una parte, la reforma a la Constitución al final del gobierno del presidente Andrés Pastrana (1998 2002) que redujo de manera transitoria las transferencias a los gobiernos locales y, de otra, la diplomacia alternativa que seis gobernadores del sur del país desarrollan contra el Plan Colombia 5 .

Debilidad del presidencialismo y del centralismo, así como del bipartidismo. La elección de alcaldes y gobernadores abrió el mapa electoral "por abajo". Desde la primera elección de alcaldes en 1998, par tidos y movimientos políticos no adscritos al partido Liberal y Conservador han ganado la representación de la administración municipal en porcentajes que oscilan entre más del $11 \%$ y menos del $37 \%{ }^{6}$ Esta aper tura política comenzó en pequeños municipios y pasó, rápidamente, a las principales alcaldías y gobernaciones del país ${ }^{7}$.

El mantenimiento de las mayorías electorales por los par tidos Liberal y Conservador no alcanza a ocultar el grado de descomposición de la unidad

\footnotetext{
${ }^{5}$ Los gobernadores de los departamentos de Nariño, Cauca, Putumayo, Caquetá, Huila y Tolima.

${ }^{6}$ En el centro del país, la ciudad capital, Bogotá, ha sido gobernada dos veces en los últimos diez años por el independiente Antanas Mokus. La cuarta ciudad de Colombia, el puerto sobre el mar Caribe Barranquilla, también ha tenido dos veces por alcalde a un independiente ex-sacer dote, Bernardo Hoyos. Al extr emo sur, próximo a la frontera con Ecuador, el municipio de Pasto fue gobernado por un exguerrillero, Antonio Navarro. Al oriente, la ciudad petrolera de Barrancabermeja tuvo a un descendiente del general Rojas por alcalde, y próximo a la frontera con Venezuela, la ciudad de Cúcuta fue gobernada por el entonces sacerdote Pauselino Camargo.
}

El departamento del Valle del Cauca, tercero en importancia económica y política, fue gobernado por el escritor in dependiente Gustavo Alvarez Gardezábal. El Cauca, departamento con una gran concentración de población india, es gobernado actualmente por el indio Flor o Tunubalá. Los departamentos de Nariño (Parmenio Cuéllar) y Tolima (Guillermo Alfonso Jaramillo) están a cargo de gobernadores en abierta ruptura y confrontación con los partidos tradicionales. nacional y territorial de tales organizaciones políticas. Las jefaturas nacionales no logran articular plataformas programáticas que impongan la disciplina de partido ${ }^{8}$. Tampoco son capaces de elaborar listas únicas para el Senado y la Cámara? De tal manera, al poder ejecutivo nacional se le encarecen los costos de transacción de leyes e iniciativas, puesto que, no pudiendo negociar con partidos unificados, transa con las múltiples facciones con representación política importante. El resultado es una cierta parálisis en la acometida de las principales reformas políticas, administrativas y sociales que urgen ante la crisis nacional ${ }^{10}$. En el nivel territorial es frecuente encontrar varios candidatos liberales disputando una alcaldía o varios líderes conservadores una gobernación. La elección popular de mandatarios locales ha acelerado el proceso de descomposición y atomización de los partidos políticos nacionales, particularmente del Liberal y Conservador. En el ámbito nacional, varios candidatos vencedores o vencidos en las contiendas presidenciales también se presentan por fuera de los programas, estructuras y disciplina de los aparatos que detentan la representación formal de los partidos liberal y conservador ${ }^{11}$.

\footnotetext{
${ }^{8}$ La descomposición de los partidos y la carencia de una identidad programática fue el resultado de haber suprimido la competencia partidista durante los largos años del Frente Nacional. El proceso de descentralización no hace otra cosa que exacerbar la confrontación entre facciones internas a los partidos por los cargos de representación popular. La crisis de los partidos tradicionales durante el Frente Nacional es tratada por Leal y Dávila (1990)
}

${ }^{9} \mathrm{La}$ crisis de los partidos nacionales explica las recurren tes propuestas tendientes a forzar la existencia de listas y voceros únicos de los partidos en los cuerpos colegiados. Lo contrario, la presentación de listas personales avaladas por los partidos, es conocida como "operación avispa", en virtud de la cual se presentaron, para las elecciones del 2002, 2.834 listas para proveer 103 curules en el Senado de la República, mientras que 6.546 listas compitieron por 165 escaños en la Cámara de Representantes.

${ }^{10}$ La debilidad de los partidos alimenta las relaciones incestuosas entre el poder ejecutivo y legislativo, mediante las cuales el primero compra costosas adhesiones a sus principales iniciativas legislativas y el segundo falla en ejercer el control político que le corresponde o paraliza al gobierno.

${ }^{11}$ Tal fue el caso en la última contienda electoral del presidente electo Alvaro Uribe Vélez (2002-2006) y de la candidata Noemí Sanin. 
Al Estado y el régimen político centralizado correspondió la construcción de partidos nacionales fuertes; a la descentralización administrativa, fiscal y política le sucede la agremiación política de los territorios. La Federación Colombiana de Municipios y la Federación Nacional de Departamentos defienden los intereses políticos de municipios y departamentos a partir de una lógica suprapartidista. La negociación entre el gobierno y los gremios políticos locales gira principalmente alrededor del monto y uso de los recursos transferidos y de las prerrogativas locales en el manejo del orden público.

El desmonte del centralismo y la crisis de los partidos nacionales estimulan la reorganización política, de muy diverso signo, alrededor de territorios. Desde el espectro político que se mueve en la legalidad se pueden mencionar las alianzas de alcaldes del Magdalena Medio contra la insurgencia, el bloque de gobernadores del sur en abierta oposición a la política nacional de substitución de cultivos ilícitos y la unidad de todo el arco iris de la clase política costeña en reclamo de la creación de la Región Caribe. El movimiento guerrillero posee una hegemonía geográfica en vastas zonas del sur y el oriente del país y la contrainsurgencia en el nor te y centro. Existe una nueva geografía política en ciernes en la que en diversos territorios imperan mayorías políticas distintas, ninguna de las cuales posee suficiente fuerza para imponerse internamente en el territorio del otro.

La temprana conversión del Ministerio de Gobierno en Ministerio del Interior, realizada por los constituyentes de 1991, se anticipó a los efectos de un proceso que ellos mismos ayudaron a acelerar. La dirección de los asuntos políticos por el gobierno nacional debe inevitablemente adecuarse a los nuevos agrupamientos geográficos mediante las prácticas de una "cancillería interna".

El resultado político de la descentralización es entonces contradictorio. Por una parte, ha generado un sistema político más pluralista, pero también más atomizado. Es propia del pluralismo la diversidad; ese no es el problema, sino la naturaleza de tal diversidad y las condiciones para su expresión. La pluralidad que se expresa en virtud del proceso eleccionario local es toda aquella que nos habita, es decir, liberales y conservadores de todas las corrientes y facciones, alternativos de der echa, centro e izquierda, movimientos sociales, indígenas, negros y religiosos, líderes empresariales, de clases medias o de extracción popular; así como también la toma o, por lo menos, la presión de los gobiernos locales por todas las fuerzas irr egulares que disputan poder en Colombia: insurgencia, contrainsurgencia y traficantes de cultivos ilícitos. Tal es el sentido de la ganancia en representatividad facilitada por la descentralización. No es un secreto para nadie la inexistencia de consensos mínimos entre todas esas fuerzas en cuanto a la política económica, el manejo de la deuda externa, el conflicto armado, los cultivos ilícitos, la reforma agraria y urbana, las políticas laborales, las relaciones externas e, incluso, el manejo de los gobiernos locales. De tal manera, el pluralismo acrecienta la ingobernabilidad, mientras no existan los acuerdos básicos sobre el modelo de desarrollo, de Estado y de sistema político que deben imperar.

\section{El pluralismo institucional y normativo}

Hasta la constitución política de 1991 existían tres niveles territoriales: la nación, los departamentos y los municipios. Los constituyentes abrier on la posibilidad de generar otras entidades territoriales: las provincias por asociación entre municipios contiguos, las r egiones por asociación entre departamentos contiguos y las entidades territoriales indígenas. Sin embargo, a doce años de promulgada la carta política, no se ha creado ninguna entidad territorial nueva, por falta de una Ley Orgánica de Ordenamiento Territorial que lo permita. El bloqueo del mapa geográfico institucional no se explica por una car encia de interés en el tema de par te de los sucesivos representantes de las fuerzas políticas de distintos territorios que han accedido a la Cámara y el Senado en este lapso. Por el contrario, a falta de una propuesta de ley, se han presentado una decena en doce años. La inmovilidad normativa resulta de un inacabado proceso de negociación en una situación de ver tiginosos cambios políticos. Muchos son los intereses en juego: la repartición de rentas estatales, la jefatura de las instituciones, los lugares espaciales en los que se conforma la represen- 
tación electoral y la articulación política entre el centro y la periferia.

A pesar de estar represada la nueva geografía electoral, administrativa y de las finanzas intergubernamentales, el modelo de organización espacial sigue en crisis y satisface a pocos. Cada ley que desarrolla la descentralización desde 1986 ha sido el producto de transacciones derivadas de correlaciones de fuerzas en cada gobierno. El resultado: un laberinto institucional en el que coexisten varios modelos de descentralización que enturbian todo el andamiaje institucional ${ }^{12}$, encarecen los costos del sistema ${ }^{13}$ y dificultan el ejercicio del gobierno a los mandatarios locales, mientras facilitan la violación de contradictorias leyes y normas reguladoras de la descentralización. Es imperiosa una ley que armonice un solo ordenamiento territorial.

Las principales leyes de descentralización tratan a todos los municipios por igual, les exigen los mismos deber es y derechos a aquellos de 10.000, 100.000, 500.000 o millones de habitantes. Es como si pretendieran uniformar las olas del mar, esfuerzo inútil e imposible. No obstante, los efectos son per versos pues incentivan, alternativamente, la ineficiencia de la administración pública o el despilfarro de sus capacidades. Unas entidades territoriales son incapaces de asumir las funciones transferidas, otras exceden en posibilidades las delegaciones recibidas. Los departamentos suelen ser muy pequeños para tar eas de desarrollo y muy grandes para la adecuada atención de todos sus municipios y para la representación de intereses de todos los poblados ante la nación. Las administraciones no pueden articular la infraestructura de comunicaciones y transporte y los recursos naturales, de capital y de trabajo que se requieren

12 Por fortuna Colombia posee una obra enciclopédica en la que se relata de manera sistemática la construcción del complejo andamiaje institucional que resulta de la aplicación del neoliberalismo, la apertura y la descentralización (González, 1997).

${ }^{13} \mathrm{El}$ déficit fiscal nacional es presionado, entre otras razones, por el mantenimiento de gastos del nivel central en funciones para las cuales ya se descentralizaron recursos. Estos gastos centrales representar on el $8 \%$ de los recursos transferidos durante 1990-1993, y el 5\% durante 1994-1999 ( $\mathrm{Za}$ pata, 2002) para apoyar el desarrollo socio-económico en los territorios; muchas veces la geografía económica regional escapa a las competencias de los departamentos.

Es verdad sabida que para las comunidades étnicas -indígenas y negras- identidad, desarrollo y cultura sólo son posibles en un espacio territorial dado; por ello, el reclamo superior es al reconocimiento de autoridades, derecho, lengua y régimen de propiedad propios en un territorio autónomo. El pluralismo institucional y normativo que tal aspiración supone es un reto mayor en la construcción de un Estado democrático contemporáneo $^{14}$.

La apertura al pluralismo institucional no se reduce al reconocimiento de los derechos de las sociedades étnicas, llamadas "menores", sino que se extiende a todo el proceso de descentralización. Crecientes son las voces de aquellos que defienden romper la uniformidad de la ley, el carácter único de la legislación y el sistema homogéneo de competencias descentralizadas.

A diez y seis años de iniciado el proceso de descentralización coexiste un creciente pluralismo político, que se manifiesta en nuevas agr emiaciones y hegemonías políticas territoriales, con un bloqueo a los cambios institucionales y normativos que las expresen. ¿Hasta cuándo? Es presumible, en un corto tiempo, el intento de afectar el viejo ordenamiento territorial, como analizamos al final de este artículo. ¿De qué manera? ¿i mpuesta o concertada, desde arriba o desde abajo?; ¿desaparecerán los departamentos en favor de las entidades territoriales regionales o se fortalecerán con nuevas funciones y recursos?; ¡obtendrán, al fin, las etnias sus territorios autónomos y recuperarán

\footnotetext{
${ }^{14}$ Los 597 resguardos indígenas poseen un poco más de 30 millones de hectáreas, que representan el 28\% del territorio nacional. Propiedad nominal que es realmente violentada por grandes proyectos de extracción de recursos naturales no renovables, narcotraficantes, paramilitares, guerrilleros, colonos y comunidades negras. Tierras que además se encuentran en un $80 \%$ en zonas escarpadas de baja productividad y zonas húmedas de escasa capa vegetal. Sin embargo, son las tierras de las aguas (ElTiempo, 28 de abril de 2003). Las comunidades negras, por su parte, poseen 122 títulos de propiedad colectiva sobre un poco más de 4,5 millones de hectár eas ( $E l$ Tiempo, 21 de mayo de 2003).
} 
los negros el retraso que poseen respecto de los indios en materia de reconocimiento constitucional de derechos comunitarios?; ; jexistirán mandatarios provinciales elegidos y cómo se representarán las fuerzas municipales en provincias y regiones?; en fin, ¿̇cambiará la bolsa de recursos descentralizados y cuáles entidades territoriales se quedarán con los factores fundamentales del poder político, institucional y económico?

\section{De la política social a la productiva}

En sentido estricto, las materias descentralizadas están todas en la órbita de las políticas sociales, en particular, el grueso de los recursos y del desarrollo normativo es absorbido por dos sectores, la educación y la salud en sus niveles bási$\cos ^{15}$. A través del proceso de descentralización el gasto público social se ha más que duplicado en diez y seis años ${ }^{16}$. El resultado ha sido un aumento en la cober tura de salud y educación en la población más pobre, un creciente número de planteles y una mayor cantidad de trabajadores vinculados a estos sectores ${ }^{17}$. Tres inquietudes matizan estos desempeños: la eficiencia, la equidad y la sostenibilidad de semejante esfuerzo.

Muchos funcionarios, organizaciones sociales y representantes políticos se cuestionan los costos de los evidentes beneficios logrados. Es presumible un mayor aumento de recursos que de cober-

${ }^{15}$ En vir tud de la Ley 715 de 2002, a las transferencias se les denomina Sistema General de Participaciones, el cual prevé destinar el $24,5 \%$ a la salud, el $58,5 \%$ a la educación y el $17 \%$ a otros gastos (DNP, 2003).

${ }^{16}$ Como proporción del PIB, entre 1986 y 2002 el gasto en salud pasó del 5,8\% al 12,6\%, y el de educación, del 4,8\% al 7,9\% (DNP, 2002).

${ }^{17} \mathrm{El}$ no acceso a salud pasó de representar el 18,3\% de la población en 1986 al 5,3\% en 2000 . Entre 1990 y 1999, la infraestructura en salud creció en centros y puestos de salud un $5 \%$, y los hospitales de segundo y tercer nivel en $11 \%$ y $20 \%$ respectivamente. En el mismo periodo, la planta de personal creció en un $20 \%$ y se duplicó la cantidad de técnicos de saneamiento. La cobertura en educación primaria aumentó desde el $72 \%$ al $75 \%$ entre 1991 y 2000 . En el mismo período, la cober tura en educación secundaria aumentó del $35 \%$ al $49 \%$. La infraestructura educativa aumentó en un $5 \%$ entre 1990 y 1993 y en un $12 \%$ entre 1994 y 2000 . La planta de personal creció un $17 \%$ entre 1990 y 1999 (CID, 2002; DNP, 2002). turas de los servicios ${ }^{18}$. Los tamaños de los planteles están por encima de su utilización y el crecimiento del númer o de funcionarios adscritos a los diferentes sectores descentralizados no siempre se traduce en una correspondiente mejoría en la calidad de los servicios ofr ecidos por el Estado. En el régimen subsidiado en salud, los intermediarios financieros -entre los giros de la nación y los hospitales- cobran caro deteriorados programas de prevención y promoción de la salud y ausentes servicios de defensa de los usuarios ante los centros, puestos y hospitales. La técnica de focalización de los beneficiarios de la salud subsidiada mediante el Sistema de Identificación de Beneficiarios - SISBEN, posee muchas fallas, deja por fuera a la mitad de los pobres del país y permite entrar al sistema una buena cantidad de personas no consideradas pobres meritorios de subsidios por los criterios de la ley ${ }^{19}$.

¿Poseen las transferencias un claro impacto en la equidad territorial y social, es decir, en la distribución de recursos a favor de los territorios y la población más deprimida del país? Un estudio del

\footnotetext{
${ }^{18}$ En la producción de un bien material como la papa, la inversión en tecnología debe lograr un incremento en el total de los bienes producidos, de tal manera que cada bulto cueste menos que antes de realizar el incremento en la inversión. La evaluación de la eficiencia en la provisión de los bienes en salud y educación no responde a este criterio de correspondencia simple entre el aumento de recursos y coberturas. Cuando en el aula de clase se pasa del pizarrón y la tiza a las computadoras y los laboratorios, se aumenta la inversión, mas no necesariamente la cantidad de bienes producidos en términos de aumento de estudiantes atendidos. Además, se obliga mantener un gasto inercial y probablemente creciente para financiar el mantenimiento, la mejora de los programas y la dotación de los medios electrónicos y de laboratorio. De la misma manera, la introducción de exámenes médicos de sangr e y orina en centros, puestos y hospitales de salud, no necesariamente conduce al aumento de la cober tura de personas, sino probablemente a generar un gasto inercial creciente para mantener los niveles de calidad que induce la inversión tecnológica.
}

${ }^{19}$ En el régimen subsidiado, los errores de exclusión de la población pobre son del $53,3 \%$ respecto de la población catalogada en los niveles 1 y 2 de pobreza por el Sisben, y del $55,2 \%$ de la población más pobre según los indicadores de necesidades básicas insatisfechas (NBI). También existen errores de inclusión de la población considerada no suficientemente pobre para hacerse beneficiaria del subsidio: éstos representan el $14,9 \%$ y el $22,1 \%$ de los indebidos beneficiarios del sistema, según se midan por niveles de pobreza del Sisben o de las NBI (CID, 2002). 
Departamento Nacional de Planeación afirma una leve tendencia distributiva del gasto público a favor de las localidades menos desarrolladas ${ }^{20}$. En cambio, los sector es urbanos siguen recibiendo mayores recursos, por persona, que los sectores rura$l^{2}{ }^{21}$. En cuanto a la equidad social, una parte de los recursos recibidos por los gobiernos locales se calculó, entre 1992 y el año 2002, según la cantidad de pobres residentes en la entidad territorial; a mayor índice de necesidades básicas, mayores transferencias por persona. Sin embargo, los recursos son recibidos por las alcaldías y los sectores de educación y salud, lo cual no garantiza, de manera automática y general, el destino del gasto hacia la población más pobre ${ }^{22}$.

En el lenguaje técnico de los economistas se afirma que el proceso descentraliza los gastos y no los ingresos; esto quiere decir que todo el andamiaje está volcado hacia la repartición territorial del presupuesto nacional en materia de políticas sociales, que se presume puede generar un gasto público más eficientemente ejecutado por los gobiernos locales que por entidades centrales. La descentralización de los ingresos supone dos tipos de reformas, una autonomía territorial para la creación de impuestos locales y una mayor distribución del conjunto de impuestos existentes entre las entidades territoriales, particularmente, la cesión de impuestos nacionales como el de la renta.

En el largo plazo, la sostenibilidad económica de la descentralización depende, para muchos, de

\footnotetext{
${ }^{20}$ Un estudio anterior del Centro de Investigaciones para el Desarrollo de la Universidad Nacional documentó lo contrario, es decir, el mantenimiento de la inercia del gasto de la época centralista a favor de las entidades territoriales con mayores recursos, con notorias excepciones como la ciudad capital -Bogotá.

${ }^{21} \mathrm{El} 65 \%$ de las transferencias tuvieron por destino, entre 1990 y 2000, las áreas urbanas, contra el 35\% para las rurales. $S$ in embargo, debe reconocerse el aumento proporcional de la inversión en las áreas rurales respecto de las urbanas entre 1990 y 1998, tendencia que se frenó a partir de la crisis económica, y por tanto, de la cantidad total del monto de las transferencias, a par tir de 1999 (DNP, 2002).

${ }^{22}$ Las reglas de repartición de los recursos fuer on modificadas por la Ley 715 de 2001; su impacto, además de la reducción de los giros para la política social cuando no crezcan los ingresos corrientes de la nación, están por medirse en los próximos años.
}

la capacidad de los gobiernos locales de estimular la generación de ingresos en sus territorios, mediante el apoyo a las actividades productivas, comerciales y financieras. Para que esto sea posible, la descentralización de la política social debe completarse con la descentralización de parte de la política económica. En las décadas del sesenta y setenta, existieron paquetes de estímulos económicos al desarrollo regional y se pretendió cerrar la brecha en el desarrollo entre las diferentes regiones, ciudades y entre las zonas rurales y urbanas. De manera paradójica, la adopción del proceso de descentralización desde la década del ochenta, sepultó las políticas de desarrollo regional, a cambio del interés por la programación territorial del gasto público social. El resultado territorial de la apertura económica, emprendida también desde la década del ochenta, ha sido el aumento de las disparidades en los índices de crecimiento y bienestar entre regiones, al interior de ellas, entre ciudades y entre el sector urbano y rural. Hoy Colombia es un país más desigual, tendencia que la descentralización de la política social no ha podido contrariar de manera significativa.

Desde la década del ochenta, han existido algunos mecanismos complementarios de la descentralización para compensar las diferencias territoriales en los índices de desarrollo y de necesidades básicas insatisfechas; por ejemplo, el Plan Nacional de Rehabilitación, el Plan Pacífico, la Red de Solidaridad Social y el componente de inversión social del Plan Colombia. Todos han sido programas aleatorios, circunstanciales y dependientes de la presidencia de la república; no obedecen a una "política de Estado", sino a la política social del presidente de turno. De tal manera, el apoyo político a los programas dentro del Estado se atempera con la inestabilidad en los objetivos y la rotación de la población y de los territorios intervenidos; todo lo cual aminora la durabilidad de los impactos de tales programas.

Se concluye entonces que ni el proceso de descentralización ni los programas sociales de los presidentes, son suficientes para incentivar dinámicas perdurables de desarrollo local. No obstante, una abundante literatura insiste en la importancia de los factores territoriales en el crecimiento económico, la distribución de los ingresos y la construcción de la democracia. Además de las políticas macro económicas generales y aquellas 
específicas para ciertos sectores industriales, comerciales, agropecuarios o financieros, el desarrollo y el bienestar están determinados por variables y políticas territoriales. Una "descentralización para el desarrollo" 23 requiere transitar de la política social a la económica. La creación y destino de los impuestos, la regulación de la explotación de los recursos naturales, las investigaciones e inversiones en ciencia y tecnología, los programas de reconversión laboral, las inversiones en infraestructura y los incentivos a la actividad económica, son algunas de las materias que pueden complementar la descentralización de la política social, dentro de una clara estrategia de desarrollo social y productivo de los territorios.

\section{5. ¿Del Estado unitario descentralizado a la regionalización?}

¿Cuál es, por lo tanto, el mejor ordenamiento territorial para incentivar el desarrollo y cuáles las relaciones entre esta respuesta y la solución política al conflicto armado?

La agenda pública en las décadas del setenta y ochenta estuvo centrada en la búsqueda de una mayor eficiencia de la administración y el gasto estatal, en los reclamos por una mayor cobertura y calidad de los servicios públicos y la construcción de un régimen político menos excluyente y más participativo. Poco a poco, en un lapso aproximado de quince años, las diferentes expectativas fueron convergiendo hacia la promoción de un proceso integral de descentralización.

En 1982, los candidatos a la presidencia de la república por el partido Conservador (Belisario Betancur), Liberal (Alfonso López Michelsen) y la disidencia liberal (Luis Carlos Galán) se comprometieron en impulsar la descentralización, aduciendo, entre otras razones, la recuperación de la legitimidad del régimen político y una mayor eficiencia de la administración estatal. La clase política de ambos partidos tradicionales acr ecentó, en las décadas del setenta y ochenta, un reclamo de mayor protagonismo de los dirigentes locales en asuntos territoriales y de política nacional. En

\footnotetext{
${ }^{23}$ Término acuñado en Colombia por Wierner (1992).
}

1983, el tercer encuentro nacional de movimientos cívicos propuso la elección popular de alcaldes y gobernadores, planes de desarrollo en cada entidad territorial, par ticipación de los usuarios en las entidades prestadoras de servicios públicos y cabildos abier tos para incentivar la participación ciudadana. También en la década del ochenta, los créditos de las agencias multilaterales empezaron a experimentar la descentralización de las políticas de cooperación al desarr ollo con participación comunitaria. Los acuerdos de paz de 1984-1985, firmados entre el gobierno de Belisario Betancur y las Fuer zas Armadas Revolucionarias de Colombia - FARC, saludaron la descentralización como espacio adecuado para democratizar el régimen político y adelantar una eventual futura reinserción del movimiento insurgente. El movimiento político que salió de tales acuerdos, la Unión Patriótica, no solo apoyó políticamente la descentralización, sino que se volcó a la conquista de alcaldías, concejos municipales, gobernaciones y asambleas depar tamentales ${ }^{24}$. Posteriormente, todos los movimientos insurgentes que pactaron un acuerdo de paz (par ticularmente el Movimiento 19 de Abril -M19-, el Partido Revolucionario de los Trabajadores -PRT-, el Ejército Popular de Liberación EPL- y una fracción del Ejército de Liberación nacional-ELN-, la Corriente Socialista, se volcaron hacia la conquista política de las administraciones locales; con desigual éxito, ha de admitirse.

La elección popular de alcaldes, la cesión del 50\% del impuesto al valor agregado de la nación a las entidades territoriales y el inicio de la descentralización de las políticas sociales básicas en 1986, fueron entonces el resultado de un consenso; o más bien, de una negociación de múltiples intereses, expectativas y racionalidades, que convergieron, todas, en apoyar el proceso más radical e integral de descentralización en América Latina hasta la fecha. Claro está que no todas las fuerzas mencionadas intervinieron en la negociación de las leyes entre el gobierno y el congreso durante los años de 1986 y 1987. Tal ausencia puede, en parte, explicar el desencanto de muchos con las reformas acometidas hasta ahora.

\footnotetext{
${ }^{24}$ La Unión Patriótica alcanzó el 8,2\% de las alcaldías, 13 concejales municipales y 24 escaños en las asambleas departamentales.
} 
La agenda pública durante la década del noventa del siglo XX y los primeros años del siglo XXI sigue marcada por la construcción de una administración estatal más eficiente y hoy, menos onerosa; los movimientos sociales siguen demandando más y mejores servicios públicos y también más oportunidades de trabajo, generación de ingresos y niveles de desarrollo; la apertura política y electoral acometida en virtud del proceso de descentralización es reconocida, pero también se denuncian y se sufren las prácticas clientelistas y la corr upción como obstáculos a la democracia y a la participación ciudadana y comunitaria en la definición de las políticas de interés colectivo.

Durante los noventa, la preocupación por el déficit fiscal, la generalización de la pobreza y la aper tura democrática ocurrieron en un escenario en el que la profundización de la aper tura económica, los efectos de la descentralización sobre el régimen político y la evolución de la confrontación armada, desencadenaron una convergencia política amplia hacia un nuevo ordenamiento territorial.

Varios efectos territoriales importantes conlleva la internacionalización de la economía. Unas actividades económicas declinan y otras florecen, así como se deprimen o activan los territorios en los que ocurren estos impactos económicos ${ }^{25}$. Por ejemplo, la ciudad de Barranquilla conoce una importante inversión de capitales atraídos por las opor tunidades de la apertura económica, una relativa paz ciudadana y una no menos relativa protección contra las principales confrontaciones armadas con el movimiento insurgente; mientras, la región cafetera sucumbe en una profunda recesión económica, depresión social e invasión territorial por el accionar armado de guerrilleros, paramilitares y actividades del narcotráfico. Alrededor de la actividad petrolera se fortalecen las clases políticas regionales, se desarrollan instituciones y se acrecientan las inversiones, mientras que los territorios de economía campesina del sur

${ }^{25}$ El editorial de la revista empresarial Dinero (octubre de 1999) propuso "superar la fallida descentralización de los '90 y construir los Estados Unidos de Colombia en el nuevo siglo" con base en economías regionales fuertes y competitivas internacionalmente. del país se pierden en la marginalidad ${ }^{26}$. Estas transformaciones en la geografía económica producen tensiones en las relaciones de fuerza económicas y políticas entre los territorios.

Cada región del país va descubriendo potencialidades y falencias en el nuevo modelo de desarrollo desencadenado por la globalización de la economía. Ya no se requiere una articulación al mercado nacional para la integración de actividades productivas, comerciales o de explotación de materias primas, a los circuitos transnacionales. En este escenario, apremia la necesidad de políticas y regulaciones económicas específicas, no solo a sectores económicos, sino a los territorios.

La geografía electoral y de las instituciones prestadoras de servicios públicos corresponde a las jurisdicciones de hace más de un siglo, los municipios y los departamentos; pero las condiciones territoriales para el desarrollo y los programas sociales requieren otros mapas, no ya exclusivamente el nacional, ni el local, sino espacios supramunicipales y supradepartamentales ${ }^{27}$. Tal es el caso del manejo de cuencas hidrográficas, bosques húmedos, recursos mineros, sistemas de transporte de los puertos a las ciudades y a los centros agroindustriales y mineros, encadenamientos productivos, comerciales y financieros, lucha contra la pobreza, perfiles epidemiológicos y programas de salud preventiva, es decir, los temas más pro-

${ }^{26}$ Por ejemplo, la alianza política de los gobernadores del sur del país (Nariño, Cauca, Tolima, Huila, Caquetá y Putumayo) se basa en que pertenecen a una región que posee los índices más bajos de inversión y de generación de empresas nuevas, a la vez que padecen una evidente precariedad en el desarrollo de su infraestructura, mientras que se vinculan a la política nacional por la presencia intensa de los diferentes actores armados en su región y al mercado internacional por una floreciente actividad del narcotráfico.

${ }^{27}$ Bajo el imperio del centralismo (1886-1996), en Colombia se generó una tendencia hacia la fragmentación de las entidades territoriales, es decir, un may or número de departamentos y municipios. Este fenómeno no fue exclusivo de Colombia, sino compartido por ejemplo en América Latina del norte con México, en América Latina del sur con Brasil y en Europa con Francia. En la actualidad, la presión hacia el reconocimiento de los gobiernos locales se acompaña de una tendencia hacia la agremiación de las entidades territoriales pequeñas en entidades territoriales más grandes, o mediante acuerdos para gestionar una serie de políticas sociales, de infraestructura y productivas entre ellas. 
metedores y dramáticos del desarrollo y de la vinculación al mercado transnacional.

En la época contemporánea toda gran ciudad tiende a absorber los municipios vecinos y, en los hechos, a crear ciudades regiones, que articulan lugares de habitación, dotación de recursos naturales, procesamiento de desechos, infraestructura de comunicación y servicios ${ }^{28}$.

En este contexto, las clases empresariales, en particular la antioqueña, vallecaucana, costeña y santandereana, extienden los vínculos y negocios más allá de sus centros históricos, y sus representantes políticos avanzan procesos de integración supradepartamentales por la vía de movimientos políticos, campañas electorales, planes de desarrollo y servicios administrativos y educativos.

Los efectos de la descentralización sobre el régimen político también presionan contra el ordenamiento electoral e institucional basado exclusivamente en municipios y departamentos ${ }^{29}$. Un efecto inmediato de la elección de alcaldes fue la tendencia a la atomización municipal de los partidos políticos, en detrimento de las redes de articulación departamentales que imperaban sobre los políticos municipales. En la Asamblea Constituyente de 1991 se dio una reacción que trató de dar reversa a tal fragmentación mediante el fortalecimiento del Departamento. La elección popular de gobernadores, la coordinación de las políticas nacionales en las jurisdicciones departamentales y la intermediación en el tránsito de cuantiosos recursos y programas de la nación a los municipios, no bastaron para evitar la crisis fiscal, política y funcional de los departamentos.

Algunos municipios se reconocen muy pequeños, con escasos recursos financieros, humanos e institucionales para adelantar obras y programas que pueden resultar más baratos y mejor gestio-

\footnotetext{
${ }^{28}$ Algunos analistas hablan incluso del remplazo de los Estado Naciones por las Ciudades Estados, lo cual -sin dudaes todavía una extrapolación exagerada de una tendencia, pero que expresa el agrupamiento de poblaciones, recursos económicos y vinculaciones al mercado regional, nacional y mundial que caracteriza las grandes ciudades del mundo.

${ }^{29}$ Una defensa de esta tesis por un ex-ministro de Estado, ex-constituyente y ex-alcalde de Bogotá se encuentra en Castro (2000).
}

nados, ante dependencias nacionales y extranjeras, cuando hacen alianza con localidades en similares circunstancias. Lo mismo ocurre con algunos departamentos. La construcción de una Región Caribe es un sueño que abrazan representantes políticos de todas las tendencias, así como organizaciones sociales y popular es costeñas. Siete encuentros para definir los pasos y las características de la Región Administrativa y de Planeación -RAP- del Caribe se han realizado desde $1981^{30}$. No menos notorio es el activismo de los llamados "gobernadores del sur", quienes redactaron las bases de un plan de desarrollo regional, poseen una posición crítica concertada respecto de los alcances actuales del proceso de descentralización y presentan un propuesta de proclamación de una República Regional Unitaria de Colombia $^{31}$. Con una menor visibilidad nacional, pero sin pausa, sectores políticos, empresarios, univ ersidades, organizaciones sociales y populares de los departamentos nororientales aprietan el ritmo de intercambios e integración con los territorios venezolanos vecinos. Un febril activismo caracteriza algunos representantes que rehacen redes de integración política en varios departamentos que corresponden a la histórica zona cafete$\mathrm{ra}^{32}$. De igual manera, alcaldes, empresarios y políticos del norte del Departamento del Valle del Cauca escudriñan la posibilidad de una articulación política e institucional nueva. Los políticos vallunos y paisas, que representan claros intereses empresariales, miran hacia los departamentos del Chocó, el antiguo y desmembrado depar tamento de Caldas, Cauca y Nariño como espacios que debieran orbitar dentro de las redes de extensión de sus proyecciones de desarrollo. Con mucha resonancia durante una época y ahora con más prudencia, se expresa una asociación de alcaldes de la región del Magdalena Medio que pretende la crea-

\footnotetext{
${ }^{30}$ Un extenso r ecuento de los movimientos políticos regionales se encuentra en Borja (1999).

${ }^{31}$ Una sustentación teórica y política de tal propuesta de regionalización se puede leer en Encuentro Nacional sobre Regiones y Provincias (2001).

${ }^{32}$ Un prominente representante de esta clase política regional, Rodrigo Rivera -que a su vez es director del partido liberal- presentó una propuesta de ley para federalizar a Colombia. La sustentación académica y política de esta propuesta se encuentra en Rivera (2001).
} 
ción de un departamento que arañaría partes del territorio a muchos otros ${ }^{33}$. Mientras tanto, los indios siguen en la brega por la creación de las Entidades Territoriales Indígenas previstas en la reforma constitucional de 1991 y cuya concreción implicaría armar regiones autónomas con partes del territorio de varios municipios y departamentos $^{34}$. Por último, incluso la población negra del Pacífico, pobre y marginada como pocas, al amparo de títulos colectivos de propiedad de la tie$\mathrm{rra}^{35}$, ocupa territorios sobre los cuales pretende incidir legalmente a partir de sus organizaciones tradicionales.

Un significativo activismo político se congrega entonces por fuera de los municipios y departamentos tradicionales. Algunas veces buscan una asociación entre municipios y, otras, expresamente, la construcción de regiones a partir de varios depar tamentos o con pedazos de los existentes. La contención de la ley orgánica de ordenamiento territorial no ha detenido el proceso económico, político y social que contiene, en la nueva geografía, las ciernes de un nuevo ordenamiento institucional.

La población colombiana está advertida, pues los medios de comunicación y los analistas políticos se lo recuerdan con insistencia: la confrontación armada se intensifica mediante el control militar de los territorios; y esta geografía supera municipios y departamentos, diseñando regiones con zonas de avanzada, en disputa, de convivencia, con corredores y retaguardias que testimonian los puntos históricos de partida. Las regiones colonizadas por los llamados "actores armados" testimonian el

\footnotetext{
${ }^{33}$ De la Asociación de Alcaldes del Magdalena Medio forman parte 63 alcaldes de municipios situados en ocho departamentos: Caldas, Boyacá, Gundinamarca, Santander, Antioquía, César, Bolívar y Magdalena.

${ }^{34} \mathrm{El}$ poco menos de un millón de habitantes indios está organizado en 84 pueblos ubicados en 280 municipios y 23 departamentos del país, y posee en propiedad colectiva algo más 30 millones de hectáreas (cerca del 28\% del territorio nacional)

${ }^{35}$ Las comunidades negras poseen cerca de 1 millón de hectáreas en propiedad colectiva. Por ejemplo, en el Chocó el departamento negro de Colombia-, el 92\% de la tierra es "legalmente" inalienable porque está adjudicada en propiedad colectiva a la población negra mayoritaria, y en menor medida, a los indios.
}

fracaso del Estado en imponer un orden político y militar en todo el territorio nacional. Son también, activos en la confrontación, botines de guerra, mecanismos para forzar un reconocimiento nacional e internacional y, por último, bastiones desde los cuales negociar una salida política al conflicto arma$\mathrm{do}^{36}$.

Se concluye entonces que tanto el proceso de globalización, el impacto político de la descentralización sobre el régimen político y la dinámica de la confrontación armada están estimulando los agrupamientos económicos, empresariales, políticos, sociales y militares en una geografía que vuelve caduco el viejo ordenamiento territorial.

\section{Regionalización y proceso de paz}

¿La tendencia hacia la regionalización del país facilita o dificulta una salida negociada al conflicto armado? Una república organizada en regiones puede fortalecer la unidad nacional mediante el reconocimiento de la diversidad que la conforma ${ }^{37}$, o puede ser el camino más rápido para exasperar las divisiones hasta fracturar el país. ¿De qué depende uno u otro desenlace? De los tiempos, que son tan importantes en política, como en música para crear la armonía o la disonancia. La regionalización se puede hacer ya, mediante una transacción entre fuerzas integradas al sistema, con la esperanza, claro está, de que los no invitados se conformen con el diseño del nuevo país hecho para todos. O la regionalización puede llegar a ser el resultado de la nueva geografía de los improbables vencedores sobre los vencidos. Finalmente, puede derivar del pacto entre partes que no reco-

${ }^{36}$ Por ejemplo, los ejércitos paramilitares extienden su influencia desde sus bases históricas en los departamentos de Córdoba y Urabá hacia zonas de presencia guerrillera en la Sierra Nevada de Santa Marta, el río Magdalena, los Montes de María y el nudo de Paramillo. La intensa presión paramilitar sobre el sur de Bolívar y la Serranía de San Lucas busca generar un dominio continuo desde el Pacífico hasta la república de Veneuela, y así lograr la hegemonía político-militar en la región costeña y repulsar la influencia guerrillera hacia el centro y sur del país (Solano, 2003).

${ }^{37}$ El profesor de la Universidad Nacional de Colombia Orlando Fals presenta una sustentación teórica e histórica de la necesidad de organizar a Colombia a partir de regiones (Fals, 2000). 
nocen derrotados; y como todo poder es territorial, el desenlace crítico de la lucha por el poder, como lo demuestra la historia de las constituciones en Colombia, suele instituir un nuevo orden territorial.

La primera característica del poder es ser fundacional, es decir, define las reglas de juego que determinan el alcance mismo de la política, los actores que participan de las decisiones y los temas sometidos al ejercicio público. De allí en adelante, la política no es más que el acontecer, más o menos tranquilo o atormentado, de un orden previamente constituido. La solución a la incógnita sobre el posible impacto de un ordenamiento regional depende entonces de las relaciones de poder económico, político y militar. La regionalización será el orden de la imposición, de la consulta o de un pacto que cobije la transacción de diversos intereses que nos comprometan en un perdurable y honorable acuerdo de paz.

Los tiempos actuales no están para construir Estados Nacionales cada vez más grandes, sino más pequeños. Hasta ahora, los Estados que se parten en varios trozos padecen de fracturas históricas, religiosas, étnicas, de lengua y cultura; características que, de manera aparente, afortunadamente, no posee Colombia. Lo que no suele advertirse son los precipicios entre el mundo rural y urbano, entre los territorios integrados al mercado nacional e internacional y las vastas zonas de un imparable proceso de colonización y extensión de la frontera agrícola, entre el mundo moderno y premoderno, entre élites acostumbradas a todo poseer y contra élites cansadas de desposesión. Tales abismos constituyen mundos de identidades históricas y culturales asentadas en territorios específicos. Entre más se profundizan los efectos diferenciadores de realidades territoriales como resultado combinado de la apertura, la crisis política y la confrontación armada, más nos acercamos a cercenar los territorios nacionales. Contrario al pensamiento mayoritario, reiterado incluso por las jefaturas políticas de los ejércitos irregulares, Colombia no está vacunada, ni blindada, contra la disolución de la unidad estatal y nacional.
No obstante la organización del territorio de manera regional puede ser una invaluable oportunidad para asentar un pacto social y político con base en el cual se profundice la equidad, el desarrollo y la democracia.

La mayor parte de la financiación del nuevo ordenamiento territorial debe provenir de los impuestos sobre la renta y complementarios y de un tributo directamente proporcional a las tasas de crecimiento regional. Da tal manera, la regionalización se fundaría en el principio de la solidaridad entre las clases sociales y entre los territorios más desarrollados con los menos. La ejecución de los recursos debiera atender, sin ambigüedad, al criterio de distribución de la riqueza; esto es, a menores niveles de desarrollo regional y may or cantidad proporcional de población pobre, mayor volumen de transferencias regionales por persona. Completa la garantía de la equidad entre territorios la creación de un Fondo de Compensación Regional, con base en el cual se logre la dotación de un mínimo de servicios sociales y condiciones para la actividad productiva similares entre las regiones, en tiempos determinados. La equidad refiere también al reconocimiento de los esfuerzos específicos que cada entidad regional realice para mejorar los niv eles relativos de desarrollo. La búsqueda de la equidad no debe, por lo tanto, desestimular a los emprendedores y exitosos, mientras premia a los acomodados y perezosos. Si no se construye un sistema de estímulos y castigos al compromiso con el desarrollo se protege la cultura rentista.

Una regionalización para el desarrollo requiere descentralizar parte de la política económica. La participación de las regiones en el manejo de los recursos naturales y los macro proyectos de interés nacional, las inversiones en infraestructura, transporte y comunicaciones, y las políticas selectiv as en favor de sectores productivos, comerciales y financieros son aspectos trascendentales que conforman parte de la agenda de un pacto territorial. Si en la actualidad, las entidades territoriales padecen una gran dependencia de las transferencias del presupuesto nacional, es porque los principales tributos pertenecen a la nación. Es necesaria una negociación sobre la repartición de 
los tributos nacionales ${ }^{38}$. El presupuesto nacional acorde con el nuevo ordenamiento territorial debiera prever una partida para el desarrollo regional que comprenda los recursos transferidos directamente a las regiones y el Fondo de Compensación Regional. Además, se deben incorporar, en la distribución del presupuesto, los der echos y responsabilidades regionales en los proyectos de interés estratégico de la nación. El pacto r egional se funda, no solo en la defensa de la autonomía de las regiones en la definición de perfiles, énfasis y prioridades específicas de desarrollo, sino en un esquema de concurrencia de las regiones en los asuntos estratégicos de la nación y, por último, en el acuerdo sobre las áreas reservadas al Estado central, garantes de la unidad nacional ${ }^{39}$. En este contexto cobraría validez, lo que hoy no es más que vana proclama constitucional, el derecho y la exigencia a cada entidad territorial de dotarse de su propio plan de desarrollo.

La conducción exclusiva de la guerra y la paz por el presidente de la república parece agotada. Sin desconocer las razones nacionales de los principales conflictos sociales, políticos y militares, deben reconocerse las diferentes dinámicas y características territoriales en el acontecer nacional, incluso en el enfrentamiento armado ${ }^{40}$. Las autoridades regionales deben participar en la agenda de las negociaciones y en un futuro y deseable pacto de paz. Hasta ahora, no solo las entidades territoriales han estado formalmente excluidas de las negociaciones de paz, sino también las principales fuerzas sociales y comunitarias con representa-

${ }^{38}$ El ex-presidente y actual Secretario General de la OEA César Gaviria escribió al respecto: "Es absolutamente indispensable que los tributos sean establecidos en las regiones o en las municipalidades, que sean cobrados por ellas, que las decisiones de inversión o de destinación sean tomadas allí" (Riv era, 2001).

${ }^{39}$ Por ejemplo, la defensa nacional, la moneda, las relaciones internacionales -sin impedir una cier ta diplomacia internacional de las r egiones-, la seguridad social, la estabilidad macroeconómica, los principios y mecanismos institucionales básicos de justicia y la participación política representativa de todas las regiones en el poder y el presupuesto nacional.

${ }^{40}$ En los últimos años se ha avanzado mucho en el estudio de las dinámicas económicas, políticas y de los conflictos sociales en difer entes regiones. Por ejemplo, se puede consultar Sánchez (1999). ción nacional o territorial. El pacto territorial que se defiende es también, un pacto social y político, por lo tanto, no puede ser exclusivo a los comandantes de los principales ejércitos, sino extenderse a las fuerzas empresariales, sociales y políticas de toda la nación. Es, por lo tanto, deseable la participación social y comunitaria en la conformación de la regiones, los planes de desarrollo territoriales y los acuerdos de paz.

Sin desconocer la multiplicidad de caminos y reformas que pueden alimentar la regionalización del país, una asamblea constituyente, que combine la representación nacional y la territorial, es recomendable para sellar el nuevo pacto nacional. Unas regiones constituidas por acuerdos políticos y con participación civil (empresarial, social y comunitaria), dotadas de planes de desarrollo propios, con autonomía política y administrativa y con facultades legislativas delimitadas, facilitarían cerrar la ancestral brecha entre territorio y Estado. En el siglo del centralismo se concentró la presencia del Estado en las principales ciudades, centros mineros y agroindustriales. Gracias al proceso de descentralización la inversión social se difunde de manera más generalizada. Las autonomías regionales con competencias en materia económica, recursos del presupuesto nacional, nuevo estatuto tributario y participación en los excedentes de los grandes proyectos de inversión y las riquezas naturales, podrían fomentar el desarrollo e integración de los mercados regionales. Un desarrollo más difuminado en todo el territorio nacional podría, en el mediano y largo plazo, resultar de un ordenamiento territorial regional, así como el centralismo estatal se correspondió con la concentración del desarrollo y del poder político en tres ciudades, Bogotá, Medellín y Cali, y sus respectivos departamentos.

El nuevo mapa territorial colombiano tomará varios años más en diseñarse. La confrontación armada, a la vez que polariza políticamente al país, contribuye a su fragmentación territorial. La reacción del ejecutivo es hacia la centralización del control sobre las transferencias y competencias descentralizadas, así como hacia una fuerte estrategia militar central con particularidades regionales mediante las Zonas de Rehabilitación y Consolidación. Por otra parte, la crisis fiscal que se extiende desde el 
colapso económico de 1999, también presiona hacia el recorte y control de las transferencias cedidas ${ }^{41}$. Estas tendencias contrarias a la profundización de la descentralización no hacen desaparecer de la agenda pública del propio gobierno el inicio del ordenamiento regional del país.

En la campaña electoral, el presidente Alvaro Uribe propuso la convocatoria a un referendo que lograra, de una sola vez, la desaparición de los 32 departamentos de Colombia para ser reemplazados por 7 u 8 regiones. Al ser elegido y antes de posesionarse, propuso una consulta popular con base en una propuesta de regionalización redactada por cuatro connotados especialistas, con base en la libertad de cada departamento de optar por la asociación regional con otro(s). Ahora, en pleno ejercicio del poder, busca facultades extraordinarias para la reforma territorial. Para el presidente el objetivo de la reforma territorial y de las regiones es la reducción de los costos de la administración pública ${ }^{42}$, para otras fuerzas políticas, de

${ }^{41}$ Por ejemplo, el Banco Mundial aconsejó al gobierno del presidente Álvaro Uribe no profundizar el proceso de descentralización en razón de la crisis económica del país, y el acuerdo con el FMI previó el recorte a las sumas transferidas para reducir el déficit fiscal.

${ }^{42}$ En el Manifiesto Democrático de Álvaro Uribe, el punto 10 dice: "Municipios vecinos que en lugar de tener cada uno su respectiva unidad de asistencia agrícola se puedan agr upar y disponer de una sola a través de un convenio con empresas solidarias de profesionales y tecnólogos. Debe haber personerías comunes para grupos de pequeños municipios o ser sustituidas por la Procuraduría Nacional. Explorar todas las posibilidades de asociación". El punto 11 dice: "La Constitución debe autorizar regiones autónomas que surjan de la fusión de depar tamentos con mecanismos que mantengan su identidad cultural. Que las regiones no sean simples entes territoriales con nuevos costos. Tres departamentos que se unan, de manera voluntaria y por iniciativa propia, podrán tener una sola gobernación, una sola asamblea. Ahorrarán, dispondrán de más recursos para lo social. La Nación debe desmontar las duplicidades y delegar más funciones y competencias en las regiones. Por ejemplo, Caminos Vecinales no debe existir en el nivel central". Y el punto 12: "Estudiaremos diferentes modalidades de alianzas entre depar tamentos, que ahorren costos para dedicar más recursos a la inversión social. Por ejemplo, que fusionen entidades operativas: departamentos vecinos podrían tener una sola Secretaría de Obras Públicas". Finalmente, el punto 13: "Las asambleas tienen que ser más austeras, pero no se deben suprimir salvo cuando sean sustituidas por parlamentos regionales. Se justifican por la representación de las subregiones de cada departamento y el control político. Los diputados no deben tener sueldo sino honorarios y seguridad social". distribuir de manera diferente el poder político y económico del país. La tentación de romper los diques institucionales y abrir la era de la regionalización es latente.

Una última palabra: mientras Colombia, al igual que otros países, busca un ordenamiento territorial que exprese las nuevas r elaciones políticas y económicas entre territorios, el proceso de internacionalización de la economía no para. Ningún Estado nacional por sí solo, y menos las regiones interior es que lo conforman, puede garantizar crecimiento y equidad por fuera de la creciente inter dependencia global. Advertimos de la impor tancia de avanzar al tiempo, como en el baile en pareja, en el nuevo diseño territorial interno y externo; acometer el primero sin el segundo es una vía expedita a la fragmentación nacional y al empobrecimiento de muchas regiones y de la población que en ellos habita.

\section{Referencias bibliográficas}

Borja, M. (1999). Estado, sociedad y ordenamiento territorial en Colombia. Bogotá: Universidad Nacional de Colombia, Editorial CEREC.

Castagna, A., I. Raposo y M. L. Woelfin (eds.) (2002). Globalización y territorio. VI eminario internacional de la RII. Rosario: RII.

Castro, J. (2000). La cuestión territorial. Bogotá: Editorial Oveja Negra.

Centro de Investigaciones para el Desarrollo (2002). Evaluación de los procesos del régimen subsidiado. Bogotá: CID, Universidad Nacional de Colombia/Ministerio de Salud.

Departamento Nacional de Planeación (2002). Evaluación de la descentralización municipal en Colombia. Bogotá: DNP.

Documento del Consejo Nacional de Política Económica y Social. Bogotá: DNP.

Encuentro Nacional sobre Regiones y Provincias (2001). Colombia: ¿República federal, regional o...? Bogotá: Fundación Friedrich Ebert/Gobernación del Tolima.

Fals, O. (2000). Acción y espacio. Autonomías en la nueva República. Bogotá: Universidad Nacional de Colombia, Tercer Mundo Editores.

González, E. (1997). El laberinto institucional colombiano, 1974-1994. Bogotá: Universidad 
Nacional de Colombia, Escuela Superior de Administración Pública/Fundación Friedrich Ebert.

Leal, F. \& A. Dávila (1990). Clientelismo. El sistema político y su expresión regional. Bogotá: Tercer mundo editores.

Sánchez, G. (1999). Conflictos regionales: la crisis del eje cafetern. Bogotá: Instituto de Estudios Políticos y Relaciones Internacionales de la Universidad Nacional de Colombia/Fundación Friedrich Ebert.
Solano, Y. (2003), El Caribe colombiano sin proyecto político regional. Santa Marta: Universidad Nacional de Colombia.

Rivera, R. (2001). Hacia un nuevo federalismo para Colombia. Bogotá: Editorial Oveja Negra.

Wierner, E. (1992). Colombia: descentralización y federalismo fiscal. Informe final de la misión para la descentralización. Bogotá: Presidencia de la República, Departamento Nacional de Planeación.

Zapata, J. G. (2002). "Misión del ingreso público". Economía y Coyuntura Política, 290.

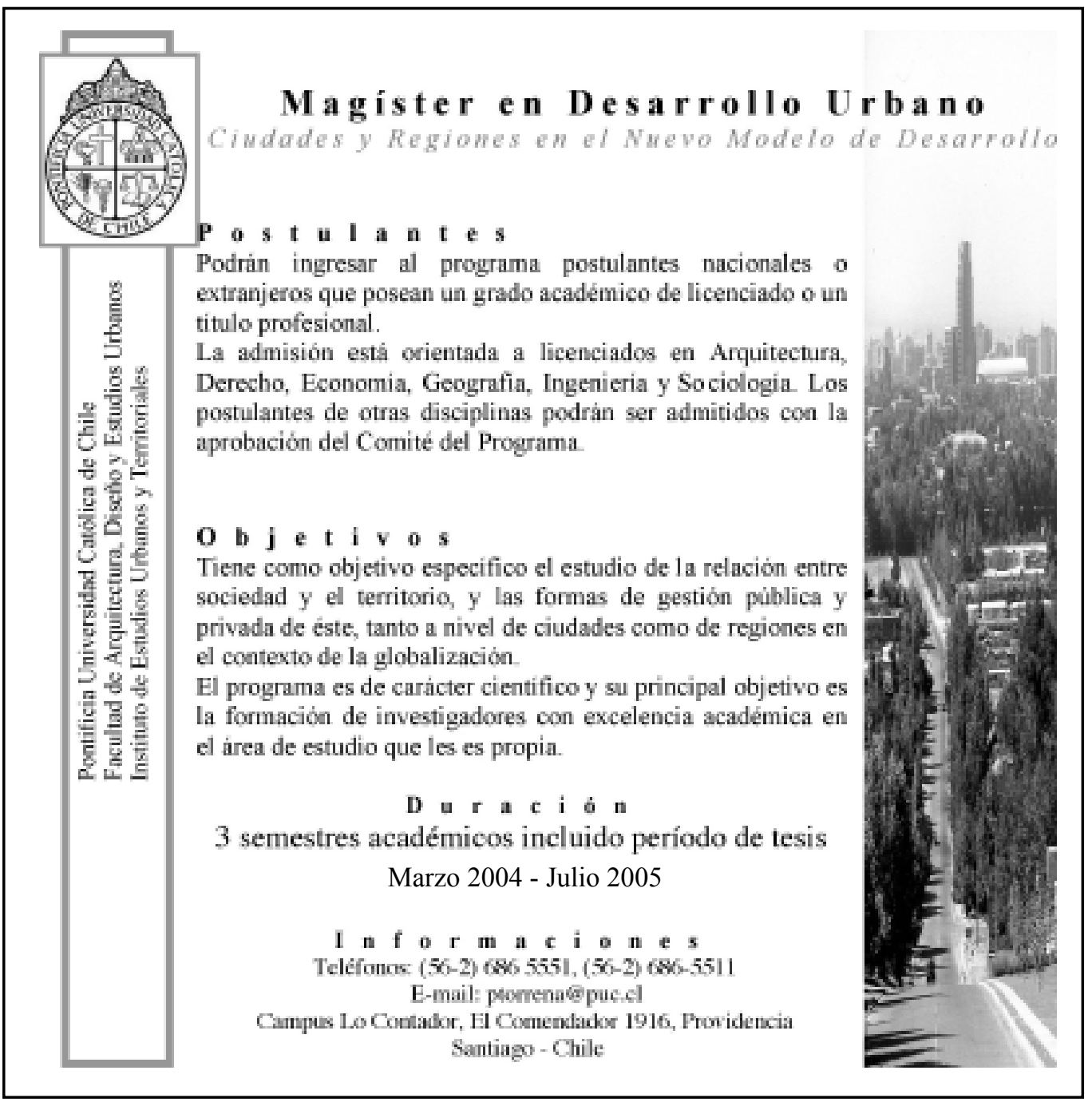

